\title{
Influence of Gold Additive on the Stability and Phase Transformation of Titanate Nanostructures
}

\begin{tabular}{|r|l|}
\hline Journal: & Physical Chemistry Chemical Physics \\
\hline Manuscript ID: & Draft \\
\hline Article Type: & Paper \\
\hline Date Submitted by the Author: & n/a \\
\hline Complete List of Authors: & $\begin{array}{l}\text { Pusztai, Péter; University of Szeged, Department of Applied and } \\
\text { Environmental Chemistry } \\
\text { Puskás, Róbert; University of Szeged, Department of Applied and } \\
\text { Environmental Chemistry } \\
\text { Varga, Erika; University of Szeged, Department of Physical Chemistry and } \\
\text { Materials Science } \\
\text { Erdohely, Andras; University of Szeged, Physical Chemistry and Material } \\
\text { Science } \\
\text { Kukovecz, Akos; Univ Szeged, Applied \& Environmental Chamistry } \\
\text { Konya, Zoltan; Univ Szeged, Applied \& Environmental Chamistry } \\
\text { Kiss, Janos; University of Szeged, }\end{array}$ \\
\hline
\end{tabular}




\section{Influence of Gold Additive on the Stability and Phase Transformation of Titanate Nanostructures}

P. Pusztai ${ }^{\mathrm{a}}$, R. Puskás ${ }^{\mathrm{a}}$, E. Varga ${ }^{\mathrm{b}}$, A. Erdőhelyi ${ }^{\mathrm{b}}$, Á. Kukovecz $^{\mathrm{a}, \mathrm{c}}$, Z. Kónya ${ }^{\mathrm{a}, \mathrm{d}}$, J. Kiss $^{\mathrm{b}, \mathrm{d}^{*}}$

${ }^{a}$ Department of Applied and Environmental Chemistry, University of Szeged, Rerrich Béla tér 1., Hungary, ${ }^{\mathrm{b}}$ Department of Physical Chemistry and Materials Science, University of Szeged, Aradi vértanuk tere1., H-6720 Szeged, Hungary ${ }^{\mathrm{c}}$ MTA-SZTE “Lendület” Porous Nanocomposite Research Group, ${ }^{\mathrm{d}}$ MTA-SZTE Reaction Kinetics and Surface Chemistry Research Group H-6720 Szeged, Rerrich Béla tér 1., Hungary,

*Corresponding author at: Department of Physical Chemistry and Materials Science, University of Szeged, Aradi vértanuk t. 1. H-6720 Szeged, Hungary. fax: +36 62546482. e-mail: jkiss@chem.u-szeged.hu 


\begin{abstract}
Gold nanoparticles were prepared and characterized on protonated (H-form) titanate nanotubes (TiONT) and nanowires (TiONW). The chemical nature and morphology of gold particles were monitored by X-ray photoelectron spectroscopy (XPS), Raman spectroscopy, $\mathrm{X}$-ray diffraction (XRD) and high resolution electron microscopy (HRTEM). The optical properties of Au-containing titanate nanowires were explored by means of ultraviolet-visible diffuse reflectance spectroscopy. The size distribution and homogeneity of gold particles depends on the reduction mode from the corresponding gold salt to metal particles. Smaller clusters $(3-8 \mathrm{~nm})$ were obtained with $\mathrm{NaBH}_{4}$ reactant at $293 \mathrm{~K}$ than with molecular hydrogen reduction. An unexpectedly high binding energy gold state was found by XPS in gold-loaded titanate nanostructures. This state was absent from the spectra of gold-loaded $\mathrm{TiO}_{2}(110)$. A likely explanation for this phenomenon, supported also by the characteristic decrease of band gap energy from $3.14 \mathrm{eV}$ to $2.50 \mathrm{eV}$ with increasing $\mathrm{Au}$ content, is that the depending on metal loading, $\mathrm{Au}$ is stabilized on titanate nanowires partially in positively charged gold form by ion exhange and also as Au clusters. Our important new finding is that the thermal annealing behavior of Au-loaded titanate nanotubes and nanowires is different. The former loose their tubular morphology and are readily transformed into anatase even at the very low temperature of $473 \mathrm{~K}$. On the other hand, gold stabilizes the layered structure of titanate nanowires up to $873 \mathrm{~K}$.
\end{abstract}

Key words: Key words: titanate nanowire, titanate nanotubes, anatase $\mathrm{TiO}_{2}, \mathrm{Au}$ nano particles, XPS, TEM, XRD, titanate Raman spectroscopy 


\section{Introduction}

One-dimensional $\mathrm{TiO}_{2}$ related nanomaterials with high morphological specificity, such as nanotubes and nanowires have attracted considerable attention due to their interesting chemical and physicochemical properties. ${ }^{1-13}$ Recently a further comprehensive review ${ }^{14}$ and $\operatorname{article}^{15}$ about the fabrication, modification and application of titania nanotubes were published. On the basis of the pioneering work of Kasuga et al., ${ }^{16}$ research efforts on titanates were at first concentrated on the hydrothermal synthesis and structure elucidation of titanate nanotubes. Recently, hydrothermal conversion of self-assembled titanate nanotubes (TiONT) into nanowires (TiONW) in a revolving autoclave was achieved in our laboratory. ${ }^{17,18}$ Titanate nanobjects are of great interest for catalytic applications, since their high surface area ${ }^{15,16}$ and cation exchange capacity provides the possibility of achieving a high metal (e.g. $\mathrm{Co}, \mathrm{Cu}, \mathrm{Ni}$, $\mathrm{Ag}$ and $\mathrm{Au}$ ) dispersion. ${ }^{11,19-21}$

Recently it was found that titanate nanostructures (nanowires and nanotubes) can stabilize gold in a very dispersed form..$^{21,23-30}$ Up to now some important titanate supported gold catalytic reactions were discovered. Gold-containing titania nanotubes were found to display higher activity than the Degussa P-25 catalyst in the photo-oxidation of acetaldehyde, ${ }^{25}$ in the photocatalytic degradation of formic acid, ${ }^{12}$ in the water-gas shift reaction $^{23}$ and in $\mathrm{CO}$ oxidation ${ }^{23,27-29}$. Nanosized gold catalyst on titanate nanowires exhibited excellent efficiency in 4-nitrophenol reduction. ${ }^{30}$ There are some examples that other noble metals supported on titanate nanostructures also perform remarkably in catalytic processes. $\mathrm{TiO}_{2}$ nanofibers decorated either with $\mathrm{Pt}$ or Pd nanoparticles show significant photocatalytic behavior as demonstrated by the decomposition of organic dyes in water, the degradation of organic stains on the surface of flexible freestanding cellulose/catalyst composite film and the generation of hydrogen from ethanol using both suspended and immobilized catalysts. The performance of the nanofiber-based catalyst materials competes with their conventional nanoparticle-based counterparts. ${ }^{31-33}$ Recently it has been shown that Rh supported on titania nanowires is a better catalyst in the hydrogenation of carbon dioxide than Rh on Degussa P-25 $\mathrm{TiO}_{2}$ and much better than that on titania nanotubes. ${ }^{34}$

The location of metal ions on the nanocrystal surface may prove important in mediating electron transfer reactions that have relevance in photocatalyis or power storage. Ion exchange allows titanate nanostructures to incorporate metal adatoms in their framework which may create another type of active center besides metal clusters. ${ }^{10,11,20,21}$ Studies in this 
direction are still scarce in the literature because of the genuine novelty of the titanate nanomaterial based photocatalytic and low-temperature thermal heterogeneous catalysis field. $\mathrm{TiO}_{2}$ structures are widely used in photochemical applications, whereas titanates offer excellent ion exchange properties, ${ }^{22}$ which are absent from rutile and anatase. Therefore, both $\mathrm{TiO}_{2}{ }^{37}$ and titanate nanostructures ${ }^{12,25,31-33}$ modified by metal nanoparticles are promising materials from the heterogeneous catalytic point of view. Morphology and chemical nature of gold additives on titanate nanotubes and nanowire are the keys to understand the processes driven by gold containing nanomaterials.

Titanate nanotubes are open-ended hollow tubular objects measuring 7-10 $\mathrm{nm}$ in outer diameter and 50-170 $\mathrm{nm}$ in length. They feature a characteristic spiral cross section composed of 4-6 wall layers. The typical diameter of their inner channel is $5 \mathrm{~nm} .{ }^{16,35}$ Titanate nanowires represent the thermodynamically most stable form of sodium trititanate under the alkaline hydrothermal conditions applied in titanate nanotube synthesis as well. (Note that the postsynthetic neutralization step converts the original $\mathrm{Na}_{2} \mathrm{Ti}_{3} \mathrm{O}_{7}$ into its hydrogen form without affecting the nanowire morphology.) Their diameter is $45-110 \mathrm{~nm}$ and their length is between 1.8 and $5 \mu \mathrm{m} .{ }^{17}$ The specific surface area of titanate nanotubes is rather large $\left(\sim 185 \mathrm{~m}^{2} \mathrm{~g}^{-1}\right)$ due to their readily accessible inner channel surface, whereas that of titanate nanowires is $\sim 20$ $\mathrm{m}^{2} \mathrm{~g}^{-1}$. According to our independent infrared spectroscopic (IR), thermogravimetric and Xray diffraction (XRD) measurements as well as literature findings ${ }^{36}$ the trititanate structure appears to be thermally deconstructed at approx. $573 \mathrm{~K}$. Annealing at higher temperatures initiates the trititanate to anatase conversion process. This phase transformation could be influenced by metal adatoms. Recently we observed Rh-induced transformation phenomena in titanate nanowire and nanotube catalysts. ${ }^{10} \mathrm{Rh}$ decorated nanowires transform into $\beta-\mathrm{TiO}_{2}$ structure, whereas their pristine counterparts' recrystallize into anatase. The formation of anatase was dominant during the thermal annealing process in both acid treated and $\mathrm{Rh}$ decorated nanotubes. Transformation to anatase was enhanced in the presence of $\mathrm{Rh} .{ }^{10}$ These examples also motivated us to study the effect of gold nanoparticles on titanate nanostructures.

In the present work we investigate the chemical nature of gold additives on titanate nanowires and nanotubes by X-ray photoelectron spectroscopy and we study the stability and phase transformation of titanate nanostractures upon gold deposition using Raman spectroscopy, X-ray diffraction (XRD) and transmission electron microscope in high resolution mode (HRTEM). 


\section{Experimental}

Titanate nanowires and nanotubes were prepared by mixing $2 \mathrm{~g}$ of anatase into $140 \mathrm{~cm}^{3} 10 \mathrm{M}$ aqueous $\mathrm{NaOH}$ solution until a white suspension was obtained, aging the suspension in a closed, cylindrical, Teflon-lined autoclave at $400 \mathrm{~K}$ for $1-72 \mathrm{~h}$ (depending on the desired product) while rotating the whole autoclave intensively at $60 \mathrm{rpm}$ around its short axis, and finally washing the product with deionized water and neutralizing with $0.1 \mathrm{M} \mathrm{HCl}$ acid solution to reach $\mathrm{pH}=7$. At this point, the titanate nanostructures slurry was filtered and dried in air at $353 \mathrm{~K} \cdot{ }^{16,17}$ Acid washing is a standard method in titanate nanotube and nanowire synthesis. It is used to exchange as much $\mathrm{Na}^{+}$ions in the structure to protons as possible. The resulting material is generally referred to as "H-form" titanate. The impurity level of the produced protonated materials was less than $1 \%$. The foreign elements determined by X-ray photoelectron spectroscopy (XPS) were $\mathrm{C}, \mathrm{Ca}$, and $\mathrm{Na}$ that remained in the product from the preparation process.

Titanate nanostructures were decorated by gold nanoparticles by two methods: (A) the $\mathrm{Au}$ containing $\mathrm{H}$-form titanate nanowires and nanotubes samples with the same actual $\mathrm{Au}$ loading $\left(\mathrm{HAuCl}_{4}\right), 1-2.5 \%$ were obtained by deposition-precipitation method ${ }^{26,28,29}$ at $\mathrm{pH}=7$ and at $343 \mathrm{~K}$, followed by treatment in $\mathrm{H}_{2}$ at $473 \mathrm{~K}$. When the reduction temperature was 573 $\mathrm{K}$, we did not observe any changes in particle sizes and morphology. The second method (B) corresponded to reducing gold with $\mathrm{NaBH}_{4}$. The sodium borohydride reduction of metal ions is a known chemical route to synthesize metal nanoparticles. ${ }^{38,39} \mathrm{HAuCl}_{4}$ solution with an appropriate concentration to provide $2.5 \mathrm{wt} \%$ gold loading was added to the wellhomogenized nanowire or nanotube suspension. After 10 minutes of stirring $50 \mathrm{mg}$ of $\mathrm{NaBH}_{4}$ (separately dissolved in $5 \mathrm{ml}$ of distilled water) was added rapidly to achieve the instantaneous formation of gold nanoparticles at $293 \mathrm{~K}$. The suspension was stirred for further 20 minutes then rinsed with distilled water thoroughly. The as-purified sample was dried overnight in air in a temperature programmed electric oven at $343 \mathrm{~K}$. Quantitative energydispersive X-ray spectroscopic (EDX) and XPS analysis showed that after washing the bulk and surface concentration of gold decreased by about 55\%. Trace amounts of Na remained in the sample after these post-synthetic treatments. Boron was undetectable in the samples.

XP spectra were taken with a SPECS instrument equipped with a PHOIBOS 150 MCD 9 hemispherical analyzer. The analyzer was operated in the FAT mode with $20 \mathrm{eV}$ pass energy. The $\mathrm{Al} \mathrm{K}_{\alpha}$ radiation $(\mathrm{h} v=1486.6 \mathrm{eV}$ ) of a dual anode X-ray gun was used as an excitation source. The gun was operated at a power of $150 \mathrm{~W}(12.5 \mathrm{kV}, 12 \mathrm{~mA})$. The energy 
step was $25 \mathrm{meV}$, electrons were collected for $100 \mathrm{~ms}$ in one channel. Typically five scans were summed to get a single high-resolution spectrum. The Ti $2 \mathrm{p}_{3 / 2}$ maximum $(458.9 \mathrm{eV})$ was used as the energy reference. The same data were obtained when $\mathrm{C}$ 1s (adventitious carbon at $285.1 \mathrm{eV})$ or $\mathrm{O} 1 \mathrm{~s}$ lattice oxygen $(530.4 \mathrm{eV})$ was used as references. The sample preparation chamber was directly connected to the measuring chamber to avoid the contamination of samples between the steps. For spectrum acquisition and evaluation both manufacturer's (SpecsLab2) and commercial (CasaXPS, Origin) software packages were used.

UV-Vis diffuse reflectance spectra were obtained relative to the reflectance of a standard $\left(\mathrm{BaSO}_{4}\right)$ using an UV/Vis spectrophotometer (OCEAN OPTICS, Typ.USB 2000) equipped with a diffuse reflectance sampling accessory. The samples were pressed into pellets of $2 \mathrm{~g} \mathrm{BaSO}_{4}$ and $50 \mathrm{mg}$ of the titanate material.

Raman spectra of slightly pressed powder samples were measured in $180^{\circ}$ backscattered geometry at $785 \mathrm{~nm}$ laser excitation (incident laser power $460 \mathrm{~mW}$ ) using an Ocean Optics QE65000 spectrometer coupled to an Ocean Optics Raman probe. Scans were integrated at $4 \mathrm{~cm}^{-1}$ resolution until the desired signal-to-noise ratio of 1000 or better was achieved (typically 30 seconds).

The bulk concentration of the elements was determined by energy-dispersive X-ray spectroscopy (EDX) performed using a Röntec Quantax $\mathrm{QX}^{2}$ spectrometer built into a Hitachi S-4700 type II cold field emission scanning electron microscope. Spectra were taken at $20 \mathrm{kV}$ acceleration voltage and quantitatively analyzed by the factory standard software after automatic background subtraction and peak fitting.

The morphology of pristine and Au modified titanate nanostructures was characterized by transmission electron microscopy (FEI Tecnai $\mathrm{G}^{2} 20$ X-Twin; $200 \mathrm{kV}$ operation voltage, x180000 magnification, 125 pm/pixel resolution). X-ray diffractometry (Rigaku MiniFlexII; $\left.\mathrm{CuK}_{\alpha}\right)$ and electron diffraction technique were used for crystal structure and crystallinity determinations. The Au particle size distribution was determined by image analysis of the HRTEM pictures using the ImageJ software. At least five representative images of equal magnification, taken at different spots of the TEM grid were first subjected to rolling ball background subtraction and contrast enhancement, and then the diameter of the metal nanoparticles in the image was manually measured against the calibrated TEM scale bar. Each diameter distribution histogram was constructed from 200 individual nanoparticle diameter measurements. ${ }^{10,11}$ 


\section{Results and discussion}

1. Preparation and characterization of gold nanoparticles on titanate nanostructures

Atomically dispersed gold can be produced on porous $\mathrm{TiO}_{2}$ and titania nanostructures (nanotubes, nanowires) by coprecipitation or deposition-precipitation methods. ${ }^{29,23-25,30}$ Although it is virtually impossible to prepare a truly monodisperse collection of metallic particles (i.e. particles of exactly the same diameter), in the past years significant progress was made in the preparation of gold particles with a narrow diameter distribution between $\sim 2-10$ nm. ${ }^{23-30,34,40,41}$ In the present work we produced gold nanoparticles on titanate nanowires and nanotubes in two ways; (A) after deposition-precipitation the reduction step was done with molecular hydrogen at $473 \mathrm{~K}$, or (B) $\mathrm{NaBH}_{4}$ was used for reduction at $293 \mathrm{~K}$ (see Experimental). Fig. 1 shows typical HRTEM images obtained with two different reduction procedures on $\mathrm{H}$-form nanowires. In the case of hydrogen reduction (Fig. 1A), the size of $\mathrm{Au}$ nanoparticles was mostly between 3.0 and $10.0 \mathrm{~nm}$, but a small fraction was observed at around $15-20 \mathrm{~nm}$ as well. A very similar result was obtained on $\mathrm{H}$-form titanate nanotubes. HRTEM and XRD measurements indicated that well-crystallized face-centered cubic gold particles were dispersed on both nanowires and nanotubes. The concentration of the gold precursor slightly affected the gold diameter distribution in the $1-2.5 \mathrm{wt} \%$ gold content range. The average size of gold was significantly smaller when the reduction was executed by $\mathrm{NaBH}_{4}$ (Fig. 1B). In this way we obtained a homogeneous distribution: the size of $\mathrm{Au}$ nanoparticles was between 3.0 and $8.0 \mathrm{~nm}$ on the $\mathrm{H}$-form titanate nanowires. The gold size distribution was very similar on the nanotubes as well, however, a small fraction of the nanoparticles had a diameter of approx. $10 \mathrm{~nm}$.

The chemical environment of the prepared gold nanoparticles was characterized by XPS. The $4 \mathrm{f}$ spectra of gold deposited on titanate nanostructures after different reduction procedures and at different gold loading are displayed in Fig. 2. For comparison the figure shows the clean gold film (thickness: $50 \mathrm{~nm}$ ) prepared on a glass plate. In the $4 \mathrm{f}$ region symmetric $4 \mathrm{f}_{5 / 2}$ and $4 \mathrm{f}_{7 / 2}$ emissions were detected (Fig. $2 \mathrm{~A}$ ). However, the features obtained on titanate nanostructures are quite different (Fig. 2B-D) insofar as two peaks are present in the reduced sample spectra for $\mathrm{Au} 4 \mathrm{f}_{7 / 2}$ at $84.0 \mathrm{eV}$ (metallic state) and at $85.8-86.3 \mathrm{eV}$.

Two different explanations can be offered for the appearance of this unusually high binding energy gold state. Core level shifts due to particle size must be considered first in the interpretation of the spectra of nanoparticles. ${ }^{42-44}$ Although this effect undoubtedly plays a role 
in the present case, the observed nearly $2 \mathrm{eV}$ binding energy shift cannot be explained satisfactorily by this way alone. In our previous paper ${ }^{21}$ the systematic increase of the binding energy with decreasing cluster size was obvious. The $A u 4 f_{7 / 2}$ peak positions were measured as a function of $\mathrm{Au}$ coverage. The peak appeared at $84.3 \mathrm{eV}$ at very low coverage (0.04 ML) on the stoichiometric $\mathrm{TiO}_{2}(110)$ surface. The position of this emission shifted slightly to lower binding energy with increasing coverage. Above $1 \mathrm{ML}$ coverage it was located at 84.0 $\mathrm{eV}$, which corresponds to the bulk position. The observed shift can be attributed to the finite size of the clusters combined with the insulating nature of the substrate, which results in a less efficient screening of the core hole formed in the photoemission process. On reduced $\mathrm{TiO}_{2}(110)$ the binding energy shift from submonolayer to monolayer is larger $(>0.6 \mathrm{eV})$ than that on the stoichiometric surface as indicated by the $\mathrm{Au} 4 \mathrm{f}_{7 / 2}$ spectra recorded at different gold coverages. It was shown experimentally that increasing the number of surface defects could enhance the nucleation probability. The deposited Au forms smaller size crystallites in higher density on thermally reduced or $\mathrm{Ar}^{+}$ion sputtered surfaces relative to the stoichiometric substrate. ${ }^{44,45}$ Although this effect certainly plays a role in the present case as well, since titanate nanowires and nanotubes obviously contain a large number of defects and irregularities, the observed nearly $2 \mathrm{eV}$ binding energy shift cannot be explained satisfactorily by this way alone. The second possible explanation is that Au may have undergone an ion exchange process. This is not possible on $\mathrm{TiO}_{2}(110)$ because of the lack of cations compensating the framework charge, however, it is quite likely to happen on titanates which are well-known for their ion-exchange ability. ${ }^{22}$ The cationic character of gold $\left(\mathrm{Au}^{+}\right)$ represents a higher binding energy position in our XPS compared to metallic gold state. When $\mathrm{Au}$ deposited as $\mathrm{Au}^{+}$ions at $1 \mathrm{eV}$ impact energy on rutile $\mathrm{TiO}_{2}$ samples was studied by XPS, ${ }^{46}$ a high binding energy state at $85.8 \mathrm{eV}$ was also observed, which further supports our explanation. Moreover, XPS showed partially charged $\mathrm{Au}^{+}$species with binding energy of 84.3-84.6 eV by deposition on nanoceria at low coverages. ${ }^{47}$ It was shown that nanoceria stabilizes small Au clusters, which may even be incorporated into ceria nanoparticles.

It can be seen in Fig. 2 that the relative intensity of the higher binding energy peak is larger at $1 \mathrm{wt} \%$ gold loading that at $2.5 \mathrm{wt} \%$ content (Fig. 2B-C). This means that at lower loading relatively more gold atoms can occupy ion exchange positions $(86.1-86.3 \mathrm{eV})$. It is remarkable that at the same loading relatively less gold occupies the ion exchange position after reduction with $\mathrm{NaBH}_{4}$ (Fig. 2D). It is very likely that the strong reducing agent reduces the positively charged gold from the ion exchange positions to metallic states during the reaction. 
An XPS-independent proof for the ion exchange can be obtained by measuring the band gap energy. Cheng et al. have provided theoretical evidence for ion exchange induced band gap reduction in a similar system (Ni-manganite). ${ }^{48}$ In our experimental work the band gap energy $\left(E_{g}\right)$ was calculated according to Beranek and $\mathrm{Kisch}^{49}$ who used the equation $\alpha=$ $\mathrm{A}\left(\mathrm{h} v-\mathrm{E}_{\mathrm{g}}\right)^{\mathrm{n}} / \mathrm{h} v$, where $\alpha$ is the absorption coefficient, $\mathrm{A}$ is a constant, $\mathrm{h} v$ is the energy of light and $\mathrm{n}$ is a constant depending on the nature of the electron transition. Assuming an indirect band gap $(\mathrm{n}=2)$ for $\mathrm{TiO}_{2}{ }^{50}$ with $\alpha$ proportional to $\mathrm{F}\left(\mathrm{R}_{\infty}\right)$, the band gap energy can be obtained from Kubelka-Munk plots (not shown) of $\left[\mathrm{F}\left(\mathrm{R}_{\infty}\right) / \mathrm{h} v\right]^{1 / 2}$ vs. $\mathrm{h} v$ as the interception at $\left[\mathrm{F}\left(\mathrm{R}_{\infty}\right) /\right.$ $\mathrm{h} v]^{1 / 2}=0$ of the extrapolated linear part of the plot. The band gap for pure titanate nanowires and nanotubes was $3.14 \mathrm{eV}$, while that for Au-doped titanate nanowire was less: $2.84 \mathrm{eV}$ at 1 wt $\%$ and $2.50 \mathrm{eV}$ at $2.5 \mathrm{wt} \% \mathrm{Au}$ content. Somewhat smaller decreases in band gap energy were measured for gold containing nanotubes (2.81 eV at $2.50 \mathrm{wt} \% \mathrm{Au}$ content). When the gold was reduced by $\mathrm{NaBH}_{4}$ at $293 \mathrm{~K}$, these values were $2.74 \mathrm{eV}$ and $2.83 \mathrm{eV}$ for nanowires and nanotubes, respectively. The pronounced decrease of the band gap of titanate nanostructures upon loading with Au suggests a very strong electronic interaction between the titanate nanostructure framework and gold, which may eventually result in an ion exchange process similar to that occurring in silver and cobalt loaded titanates. ${ }^{11,20}$ In our previous study $^{20}$ it was observed that the band gap decreased from $3.14 \mathrm{eV}$ to $2.41 \mathrm{eV}$ with increasing Co content up to $2 \mathrm{wt} \%$ cobalt content. This drastic reduction was not observed when Co was deposited in a similar way on commercial $\mathrm{TiO}_{2}$. Recently a facile method was also developed to attach transition metal ions $\left(\mathrm{Cr}^{3+}, \mathrm{Mn}^{2+}, \mathrm{Fe}^{2+}, \mathrm{Co}^{2+}, \mathrm{Ni}^{2+}\right.$ and $\left.\mathrm{Cu}^{2+}\right)$ to the surface of anatase $\mathrm{TiO}_{2}$ nanorods. ${ }^{51}$

We may conclude that the higher binding energy XPS peak $(85.8-86.4 \mathrm{eV})$ is due primarily to gold located in cation positions and - to a lesser extent - to gold clusters which are in well-dispersed form. The ratio of these two components depends on the metal content and the preparation method. Remarkable conclusions can be drawn from the XPS intensity changes during heat treatment (Fig. 3). When the gold containing nanowires $(2.5 \%)$ were treated at $473 \mathrm{~K}$ and at $673 \mathrm{~K}$ in vacuum for $60 \mathrm{~min}$, the higher binding energy peak remained at $86.4 \mathrm{eV}$, however, its intensity decreased only slightly (Fig. 3A). This means that the heat treatment did not induce any significant gold segregation from ion exchange position. Interestingly, at same metal loading lower $\mathrm{Au} 4 \mathrm{f}$ XPS intensities were measured in the case of nanotubes (Fig. 3B). It is very likely that a significant part of gold clusters occupy appropriate positions in the inner channel of the tube instead of the outer nanotube shell. A rough semiquantitative XPS analysis indicates that nearly $75 \%$ of the gold could be located in the inside 
of the tube. Further intensity changes (50\%) were measured above $473 \mathrm{~K}$ heat treatment. This change is most likely due to further gold penetration into the tube as well as to the morphological transformation of the tube structure induced by gold adatoms (see below).

2. Phase stability and phase transformation of titanate nanostructues upon gold loading

Raman spectra of acid washed H-form titanate nanotubes and nanowires are presented in Fig. $4 \mathrm{~A}$ and $4 \mathrm{~B}$ together with the spectrum of a reference anatase sample. The spectra of synthesized nanostructures match previous trititanate results where peaks in the $400-1000 \mathrm{~cm}^{-}$ ${ }^{1}$ region were assigned to Ti-O-Ti stretching vibrations. ${ }^{52,53}$ The thermal behavior of the samples basically confirms our independent thermogravimetric and XRD measurements as well as literature findings ${ }^{53}$ insofar as the trititanate structure appears to be deconstructed at around $673 \mathrm{~K}$ (Fig. 4A). Peaks at 393, 514 and $636 \mathrm{~cm}^{-1}$ are assigned to the $\mathrm{B}_{1 \mathrm{~g}}, \mathrm{~A}_{1 \mathrm{~g}}$, and $\mathrm{E}_{2 \mathrm{~g}}$ modes of anatase, respectively. ${ }^{52} \mathrm{~A}$ characteristic difference between the behavior of titanate nantubes and nanowires is that in heat treated nanotubes the $\mathrm{E}_{2 \mathrm{~g}}$ mode is found at exactly the anatase position $\left(636 \mathrm{~cm}^{-1}\right)$ from $573 \mathrm{~K}$ onward, whereas in nanowires this mode experiences a gradual red shift from $648 \mathrm{~cm}^{-1}$ at $573 \mathrm{~K}$ to $636 \mathrm{~cm}^{-1}$ at $873 \mathrm{~K}$ (Fig. 4B). A similar effect was observed by Du et al. ${ }^{54}$ and Scepanovic et al. ${ }^{55}$ in their in situ temperature-dependent Raman studies of nanocrystalline anatase. They argued that defects and nonstoichiometric composition could have a pronounced effect on the position of the soft $\mathrm{E}_{\mathrm{g}}$ modes. Adopting this argument to one-dimensional trititanates suggests that the thin and hollow structure of nanotubes is more easily converted to defect-free anatase than the bulky nanowires.

Figures $4 \mathrm{C}$ presents the Raman spectra of $2.5 \mathrm{wt} \% \mathrm{Au}$ loaded titanate nanotubes as a function of heat treatment temperature. The transformation of Au loaded nanotubes features to anatase features starts immediately with the heat treatment. The characteristic anatase peaks at 393,514 and $636 \mathrm{~cm}^{-1}$ (assigned to the $\mathrm{B}_{1 \mathrm{~g}}, \mathrm{~A}_{1 \mathrm{~g}}$ and $\mathrm{E}_{2 \mathrm{~g}}$ modes, respectively) appeared already at $473 \mathrm{~K}$. This shows that gold catalyses the transformation of the tube structure to anatase. It seems that this catalytic ability of $\mathrm{Au}$ is somewhat higher than that of $\mathrm{Rh}$ under the same experimental conditions. In the case of Rh adatoms a clear anatase phase could be identified at $673 \mathrm{~K}$ in the Raman spectra. ${ }^{10}$

A markedly different Raman spectral feature was observed in the case of Au loaded titanate nanowires (Fig. 4D). The spectra taken at different temperatures preserved the features corresponding to the wire-like structure with some spectral bordering. Moreover, 
there were no sign of anatase structure formation. These Raman results are consistent with our independent XRD and HRTEM measurements.

For comparison the structure and thermal behavior of gold-free titanate nanostructures were also studied in present work by X-ray diffraction. As XRD patterns show (Fig. 5A), the acidic treatment resulted in the degradation of the initial crystal structure of titanate nanotubes, which manifested in the disappearance of the reflection characteristic of the tubular interlayer distance $\left(2 \Theta=\sim 10^{\circ}\right)$. Protonation also induced the transformation of the titanate nanostructure to anatase form. ${ }^{10}$ Thermal treatment below $673 \mathrm{~K}$ had no significant effect on the crystal structure; however, at elevated temperature the anatase formation became relevant as evidenced by the appearance of the anatase reflections. The formation of anatase dominated the thermal annealing process from $673 \mathrm{~K}$ as indicated by the appearance of anatase reflections (101), (004), (200), (105), (211) and (204) at 25.3 $, 37.8^{\circ}, 48.1^{\circ}, 53.9^{\circ}$, $55.1^{\circ}$ and $62.4^{\circ}$, respectively.

When the H-form titanate nanotubes were decorated with $2.5 \mathrm{wt} \%$ gold adatom, anatase reflections appeared already at $473 \mathrm{~K}$ indicating that the transformation from the trititanate to anatase is very advantageous (Fig. 5B). For comparison it is worth mentioning that gold is a better catalyst for this transformation than rhodium. ${ }^{10}$ Moreover, the presence of sodium retards the transformation of titanate into $\mathrm{TiO}_{2}$, thus shifting the formation of anatase phase to higher temperatures. ${ }^{12}$ When the gold decoration procedure (reduction with hydrogen) resulted in some larger crystallites, extra reflexions due to gold were also detected.

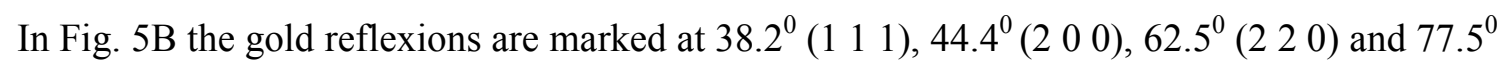
(3 111$)$.

$\mathrm{H}_{2} \mathrm{O}$ washed pristine nanowires feature a mixture of different crystalline titanate forms, mostly $\beta-\mathrm{TiO}_{2}$ and $\mathrm{H}_{\mathrm{x}} \mathrm{Na}_{(2-\mathrm{x})} \mathrm{Ti}_{3} \mathrm{O}_{7}$ as shown in the XRD patterns (Fig. 6A). The $\beta-\mathrm{TiO}_{2}$ phase was identified on the basis of its reflections with Miller indices of $\left(\begin{array}{lll}2 & 0 & 0\end{array}\right)$,

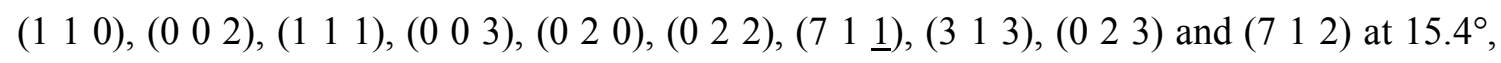
$24.9^{\circ}, 28.6^{\circ}, 29.4^{\circ}, 43.5^{\circ}, 48.5^{\circ}, 57.3^{\circ}, 58.3^{\circ}, 61.7^{\circ}, 68.2^{\circ}$ and $76.8^{\circ}$, respectively. The $\mathrm{H}_{\mathrm{x}} \mathrm{Na}_{(2-\mathrm{x})} \mathrm{Ti}_{3} \mathrm{O}_{7}$ phase was identified on the basis of its reflections with Miller indices of ( $\left.\begin{array}{lll}0 & 0 & 1\end{array}\right),\left(\begin{array}{lll}1 & 0 & 1\end{array}\right),\left(\begin{array}{lll}0 & 1 & 1\end{array}\right),\left(\begin{array}{lll}3 & 0 & 0\end{array}\right),\left(\begin{array}{lll}2 & 0 & 3\end{array}\right)$ and $\left(\begin{array}{lll}4 & 0 & 1\end{array}\right)$ found at $10.5^{\circ}, 15.8^{\circ}, 25.7^{\circ}, 29.9^{\circ}, 34.2^{\circ}$ and $43.9^{\circ}$, respectively. Acidic treatment (H-form) also resulted in crystallinity degradation. The crystal transformation is continuous during the thermal annealing process. XRD patterns recorded from a sample annealed at $473 \mathrm{~K}$ and $573 \mathrm{~K}$ indicated the collapse of the layered structure and the appearance of an anatase phase with low crystallinity. At higher temperatures the formation of the anatase phase becomes dominant as demonstrated by the 
appearance of the characteristic anatase reflections (lll $\left.\begin{array}{lll}1 & 0 & 1\end{array}\right),\left(\begin{array}{lll}0 & 0 & 4\end{array}\right),\left(\begin{array}{lll}2 & 0 & 0\end{array}\right),\left(\begin{array}{lll}1 & 0 & 5\end{array}\right),\left(\begin{array}{lll}2 & 1 & 1\end{array}\right)$ and (2 04 ) at $25.3^{\circ}, 37.8^{\circ}, 48.1^{\circ}, 53.9^{\circ}, 55.1^{\circ}$ and $62.4^{\circ}$. The process is accompanied by the loss of peak intensities at positions corresponding to the titanate interlayer distance $\left(\sim 10^{\circ}\right) \beta$ titanate structural reflections $\left(\begin{array}{lll}1 & 0 & 1\end{array}\right)$ at $15.8^{\circ}$ and $\left(\begin{array}{lll}3 & 0 & 0\end{array}\right)$ at $29.9^{\circ}$.

The nanowires preserve the wire-like morphology during the heat treatment up to 873 K. However, more and more textural discontinuities can be observed at higher temperatures. The holey structure can be attributed to the continuous transformation of protonated titanate nanostructures to $\mathrm{TiO}_{2}$ (anatase) followed by water formation and release from the structure. This processes results in the rearrangement of the anatase crystals and the appearance of voids in the structure of the nanowire (Figure 6A).

The XRD profiles of gold decorated nanowires are shown in Fig. 6B as a function of heat treatment. The most important result is that unlike in titanate nanotube, gold did not cause any phase transformations in titanate nanowires. Neither anatase phase formation nor $\beta$ $\mathrm{TiO}_{2}$ structure development were detected by XRD. The visible reflections can all be assigned to gold particles: $38.2^{\circ}\left(\begin{array}{lll}1 & 1 & 1\end{array}\right), 44.4^{\circ}\left(\begin{array}{lll}2 & 0 & 0\end{array}\right), 64.5^{\circ}\left(\begin{array}{lll}2 & 2 & 0\end{array}\right)$ and $77.5^{\circ}\left(\begin{array}{lll}3 & 1 & 1\end{array}\right)$. It is worth noting that the effect of gold adatoms on the structure and stability of titanate nanowires is significantly different from those of $\mathrm{Rh}$. In our previous studies it was demonstrated that $\mathrm{Rh}$ induces the transformation of the wire structure to $\beta-\mathrm{TiO}_{2}$ above $573 \mathrm{~K}^{10}$

TEM images demonstrate the tubular morphology of the as-synthesized titanate nanotubes with a diameter of $\sim 7 \mathrm{~nm}$ and length up to $80 \mathrm{~nm}$ (not shown here). The acid washing process resulted in a mild destruction of the inner and outer nanotube walls (Fig. 7A). In agreement with the XRD results no morphological degradation could be observed after heat treatment up to $573 \mathrm{~K}$. At higher temperatures the tubular structure started to collapse and transform into rod-like nanostructures (Fig. 7A). At $873 \mathrm{~K}$ the tubular morphology totally collapsed that resulted in short nanorods and $\mathrm{TiO}_{2}$ nanoparticles with an average diameter of $\sim 10 \mathrm{~nm}$. However, when the titanate nanotubes were decorated with gold, the tube structure was destroyed as low as at $473 \mathrm{~K}$. The HRTEM images are presented from $473 \mathrm{~K}$ in Fig. 8B-D in two resolutions; in $100 \mathrm{~nm}$ and $20 \mathrm{~nm}$, respectively. For comparison Hform titanate nanotubes without gold are also displayed in Fig. 8A. The morphology did not change any further up to $878 \mathrm{~K}$. These HRTEM results agree well with our Raman and XRD findings (Fig. 4 and Fig. 5) and confirm that the gold additive promotes the development of anatase phases. 
The titanate nanowire TEM results presented in Fig. 7B confirm that the wire-like morphology is preserved up to $873 \mathrm{~K}$ during heat treatment, and they also provide morphological evidence to support the hypothesis presented above about water loss being responsible for the appearance of textural discontinuities.

HRTEM images of gold-decorated H-form titanate nanowires subjected to annealing at different temperatures are shown in two resolutions $(100 \mathrm{~nm}$ and $20 \mathrm{~nm})$ in Fig. 9B-D. A characteristic image of pristine $\mathrm{H}$-form titanate nanowires is also presented in Fig. 9A as reference. In agreement with the XRD results, the HRTEM images have confirmed that the nanowires preserve their wire-like morphology up to $873 \mathrm{~K}$. Our important new finding is that the thermal annealing behavior of Au loaded titanate nanotubes and nanowires is different. The former lose their tubular morphology and are readily transformed into anatase even at the very low temperature of $473 \mathrm{~K}$. On the other hand, gold stabilizes the layered structure of titanate nanowires up to $873 \mathrm{~K}$. The morphology stabilization effect of gold was independent from the method used for its reduction. HRTEM results displayes in Fig. 10 show that the wire-like morphology is stable with the temperature even the gold nanoparticles were prepared by $\mathrm{NaBH}_{4}$ reactant. It seems that the effect gold is different from that of rhodium ${ }^{10}$ as $\mathrm{Rh}$-decorated nanowires have been shown to transform into $\beta-\mathrm{TiO}_{2}$ earlier.

\section{Conclusions}

$\mathrm{Au}$ nanoparticles were prepared and characterized on protonated (H-form) titanate nanotubes and nanowires. The chemical nature and morphology of gold particles were monitored by XPS, Raman spectroscopy, XRD and HRTEM. The optical properties of Au-containing titanate nanowires were explored by ultraviolet-visible diffuse reflectance spectroscopy.

1. The size distribution and homogeneity of gold particles depend on the method used for reducing the dissolved gold salt into deposited nanoparticles. Smaller clusters (3-8 $\mathrm{nm})$ were obtained with $\mathrm{NaBH}_{4}$ reactant at $293 \mathrm{~K}$ than with molecular hydrogen reduction at 473 K.

2. An unexpectedly high binding energy gold state was found by XPS in gold-loaded titanate nanostructures. This state was absent from the spectra of gold-loaded $\mathrm{TiO}_{2}(110)$ and gold thick film prepared on glass. A likely explanation for this phenomenon is that the depending on metal loading, $\mathrm{Au}$ is stabilized on titanate nanowires partially in positively charged gold form by ion exhange and also as $\mathrm{Au}$ clusters. This hypothesis is further 
supported by the characteristic decrease of band gap energy from $3.14 \mathrm{eV}$ to $2.50 \mathrm{eV}$ with increasing $\mathrm{Au}$ content.

3. Our important new finding is that the thermal annealing behavior of $\mathrm{Au}$ loaded titanate nanotubes and nanowires is different. The former loose their tubular morphology and are readily transformed into anatase even at the very low temperature of $473 \mathrm{~K}$. On the other hand, gold stabilizes the layered structure of titanate nanowires up to $873 \mathrm{~K}$. Without gold adatoms the pristine titanate nanowires transform into anatase above $673 \mathrm{~K}$. All these morphological changes - caused either by heat treatment or by a metal induced phase transformation - should be considered in the interpretation of certain catalytic reaction mechanisms or other physical chemical processes conducted on titanate nanostructures. It seems that gold adatoms have the ability to stabilize the wire-like morphology of nanostructured trititanates.

\section{Acknowledgements}

The financial support of the TÁMOP-4.2.2.A-11/1/KONV-2012-0047, TÁMOP4.2.2.A-11/1/KONV-2012-0060 and the Hungarian Scientific Research Fund OTKA NN 110676 is acknowledged. The authors thank gratefully the preparation of the Au decorated titanate nanocomposites to Mrs. Kornélia Baán and the XRD measurements to Mr. László Nagy.

\section{References:}

1 D.V. Bavykin, J.M. Friedrich, F.C. Walsh, Advanced Mater., 2006, 18, 2807-2824.

2 M. Hodos, E. Horváth, H. Haspel, Á. Kukovecz, Z. Kónya, I. Kiricsi, Chem. Phys. Lett., 2004, 399, 512-515.

3 G.K. Mor, K. Shankar, M. Paulose, O.K. Varghese, C.A. Grimes, Nano Lett., 2005, 5, 191195.

4 S. Kubota, K. Johkura, K. Asanuma, Y. Okouchi, N. Ogiwara, K. Sasaki, T. Kasuga, J. Mater. Sci.: Mater. Med., 2004, 15, 1031-1035.

5 L. Kavan, M. Kalbac, M. Zukalova, I. Exnar, V. Lorenzen, R. Nesper, M. Graetzel, Chem. Mater., 2004, 16, 477-485.

6 D. Bavykin, A.A. Lapkin, P.K. Plucinski, J.M. Friderich, F.C. Walsh, J. Phys. Chem. B, 2005, 109, 19422-19427.

7 R. Huang, F. Chung, E.M. Kelder, J. Electrochem. Soc., 2006, 153, A1459-A1465. 
8 R. Dominko, E. Baudrin, P. Umek, D. Arcon, M. Gaberscek, M. Jamnik, J. Electrochem. Commun., 2006, 8, 673-677.

9 M.T. Byrne, J.M. McCarty, M. Bent, R. Blake, Y.K. Gun'ko, E. Horváth, Z. Kónya, Á.

Kukovecz, I. Kiricsi, J.N. Coleman, J. Mater. Chem., 2007, 17, 2351-2358.

10 G. Pótári, D. Madarász, L. Nagy, B. László, A. Sápi, A. Oszkó, Á. Kukovecz, A.

Erdőhelyi, Z. Kónya, J. Kiss, Langmuir, 2013, 29, 3061-3072.

11 D. Madarász, G. Pótári, A. Sápi, B. László, C. Csudai, A. Oszkó, Á. Kukovecz, A.

Erdőhelyi, Z. Kónya, J. Kiss, J. Phys. Chem. Chem. Phys., 2013, 15, 15917-15925.

12 A. Turki, H. Kochkar, C. Guillard, G. Berhault, A. Ghorbel, Appl. Catal. B:

Environmental, 2013, 138-139, 401-415.

13 P. Yang, D.K. Zhong, M. Yuan, A.H. Rice, D.R. Gamelin, C.K. Luscombe, Phys. Chem.

Chem. Phys., 2013, 15, 4566-4572.

14 H.-H Ou, S.-L. Lo, Separ. Purif. Technol., 2007, 58, 179-191.

15 L. Torrente-Murciano, A.A. Lapkin, D. Chadwick, J. Mater. Chem., 2010, 20, 6484-6489.

16 T. Kasuga, M. Hiramatsu, A. Hoson, T. Sekino, Langmuir, 1998, 14, 3160-3163.

17 E. Horváth, Á. Kukovecz, Z. Kónya, I. Kiricsi, Chem. Mater., 2007, 19, 927-931.

18 Á. Kukovecz, M. Hodos, E. Horváth, G. Radnóczi, Z. Kónya, I. Kiricsi, J. Phys. Chem. $B$, 2005, 109, 17781-17783.

19 X. Sun, Y. Li, Chem. Eur. J., 2003, 9, 2229-2238.

20 F. Cesano, S. Bertarione, M.J. Uddin, G. Agostini, D. Scarano, A. Zeccina, J. Phys. Chem. C, 2010, 114, 169-178.

21 J. Kiss, P. Pusztai, L. Óvári, K. Baán, G. Merza, A. Erdőhelyi, Á. Kukovecz, Z. Kónya, eJ. Surf. Sci. and Nanotechnol. 2014, 12, 252-258.

22 D. Madarász, I. Szenti, A. Sápi, J. Halász, Á. Kukovecz, Z. Kónya, Chem. Phys. Lett., 2014, 591, 161-165.

23 T. Akita, M. Okumura, K. Tanaka, K. Ohkuma, M. Kohyama, T. Koyanagi, M. Data, S.

Tsubota, M. Haruta, Surf. and Interf. Anal., 2005, 37, 265-269.

24 V. Idakiev, Z. Yuan, T. Tabakova, B.L. Su, Appl. Catal. A: General, 2005, 281, 149-155.

25 S.S. Malwadkar, R.S. Gholap, S.V. Awante, P.V. Korake, M.G. Chaskar, N.M. Gupta, N.M. Photochem. Photobiol. A: Chem., 2009, 203, 24-31.

26 Á. Kukovecz, G. Pótári, A. Oszkó, Z. Kónya, A. Erdőhelyi, J. Kiss, Surf. Sci., 2011, 605, 1048-1055.

27 M. Mendez-Cruz, J. Ramirez-Solis, R. Zanella, Catal. Today, 2011, 166, 172-179. 
28 S. Tsubota, M. Haruta, T. Kobayashi, A. Ueda, A.; Nakahara, in: G. Poncelet et al., Eds., Preparation of Catalysts V, Elsevier Science B.V. 1991, pp. 695-704.

29 M. Haruta, Catal. Today, 1997, 36, 153-166.

30 G. Chen, F. Xue, Z. Chen, X. Si, X Zheng, J. Huang, S. Massey, NANO, 2014, 9, 14500391450046.

31 M-C. Wu, A. Sápi, A. Avila, M. Szabó, J. Hiltunen, G. Tóth, Á. Kukovecz, Z. Kónya, R. Keiski, W-F. Su, H. Jantunen, K. Kordás, Nano Research, 2011, 4, 360-369.

32 M-C. Wu, J. Hiltunen, A. Sápi, A. Avila, W. Larsson, H.-C. Liao, M. Huuhtanen, G. Tóth, A. Shchukarev, N. Laufer, Á. Kukovecz, Z. Kónya, J.-P. Mikkola, R. Keiski, W.-F.Chen, H. Jantunen, P.M. Ajayan, R. Vajtai, K. Kordas, ACS Nano, 2010, 5, 5025-5030.

33 M.C. Wu, G. Tóth, A. Sápi, A. Leino, Z. Kónya, Á. Kukovecz, W.F. Su, K. Kordás, J. Nanosci. Nanotech., 2012, 12, 1421-1424.

34 M. Tóth, J. Kiss, A. Oszkó, G. Pótári, B. László, A. Erdőhelyi, Topics in Catal., 2012, 55, 747-756.

35 S. Zhang, T. Y. Peng, Q. Chen, G. H. Du, G. Dawson and W. Zhou, Phys. Rev. Lett., 2003 91, 256103-256105.

36 T. Ohsaka, F. Izumi and Y. Fujiki, J. Raman Spec., 1978, 7, 321-325.

37 M. A Henderson, Surf. Sci. Rep., 2011, 66, 185-297.

38 G. N. Glavee, K.J. Klabunde, C.M. Sorensen, G.C. Hadjipanayis, Inorganic Chem., 1995, 34, 28-35.

39 E.A. Sterling, J. Stolk, L. Hafford, M. Gross, Metallurgical and Materials Trans., 2009, 40A, 1701-1709.

40 F. Boccuzzi, A. Chiorino, M. Manzoli, P. Lu, T. Akita, S. Ichikawa, M. Haruta, J. Catal., 2001, 202, 256-267.

41 J. Kiss, L. Óvári, A. Oszkó, G. Pótári, M. Tóth, K. Baán, A. Erdőhelyi, Catal. Today, 2012, 181, 163-170.

42 C.R. Henry, Surf. Sci. Rep., 1988, 31, 231-233, 235-325.

43 S. Peters, S. Peredkov, M. Neeb, W. Eberhardt, M. Al-Hada, Surf. Sci., 2013, 608, 129134.

44 B.K. Min, W.T. Wallace, D.W. Goodman, Surf. Sci., 2006, 600, L7-L11.

45 A.M. Kiss, M. Svec, A. Berkó, Surf. Sci., 2006, 600, 3352-3360.

46 C. Fan, T. Wu, S.L. Anderson, Surf. Sci., 2005, 578, 5-19.

47 M. Baron, O. Bondarchuk, D. Stacchiola, S. Shaikhutdinov, H.-J. Freund, J. Phys. Chem.

C, 2008, 113, 6042-6049. 
48 J.R. Huang, H. Hsu, C. Cheng, J. Magnetism and Magnetic Materials, 2014, 358-359, 149-152.

49 R. Beranek and H. Kisch, Photochem. Photobiol. Sci., 2008, 7, 40-48.

50 H. Tang, K. Prasad, R. Sanilines, P. E. Schmid, F. Lewy, J. Appl. Phys., 1994, 75, 20422047.

51 C. Balasanthiran, J.D. Hoefelmeyer, Chem. Commun., 2014, 50, 5721-5724.

52 R. Ma, K. Fukuda, T. Sasaki, M. Osada, Y. Bando, J. Phys. Chem. B, 2005, 109, 62106214.

53 T. Oshaka, F. Izumi, Y. Fujiki, J. Raman Spectrosc., 1978, 7, 321-324.

54 Y.L. Du, Y. Deng, M.S. Zhang, J. Phys. Chem. Solids, 2006, 67, 2405-2408.

55 M.J. Scepanovic, M. Grujic-Brojcin, Z.D. Dohcevic-Mitrovic, Z.V. Popovic, Sci. Sintering, 2009, 41, 67-73.

\section{Legend of Figures}

Fig. 1. HRTEM image on Au decorated $\mathrm{H}$-form titanate nanowires obtained with $\mathrm{H}_{2}$ reduction (A) and obtained with $\mathrm{NaBH}_{4}$ reduction (B). The corresponding particle size distributions are also shown. The gold contents were $2.5 \mathrm{wt} \%$ in both cases.

Fig. 2. Au $4 \mathrm{f}$ XPS on differentially prepared Au/titanate samples: (A) clean Au film, (B) 1 wt $\%$ Au/titanate nanowire obtained by $\mathrm{H}_{2}$ reduction at $473 \mathrm{~K}$, (C) $2.5 \mathrm{wt} \% \mathrm{Au} /$ titanate nanowire obtained by $\mathrm{H}_{2}$ reduction at $473 \mathrm{~K}$, (D) $2.5 \% \mathrm{Au} /$ titanate nanowire obtained by $\mathrm{NaBH}_{4}$ reduction at $293 \mathrm{~K}$.

Fig. 3. Au 4f XPS on Au loaded H-form titanate nanowires (A) and nanotubes (B) at $2.5 \mathrm{wt} \%$ gold content after heat treatment in vacuum for $60 \mathrm{~min}$.

Fig. 4. Normalized Raman spectra of the thermal behavior of H-form titanate nanotubes (A) and nanowires (B). Graphs C and D illustrate the thermal behavior of Au loaded titanate nanotubes and wires, respectively. The commercial anatase reference sample is shown at the top of each spectra. 
Fig. 5. XRD of $\mathrm{H}_{2} \mathrm{O}$ washed and $\mathrm{H}$-form titanate nanotubes (upper part) and $\mathrm{Au}$ loaded $(2.5 \%)$ nanotubes (lower part) as a function of annealing temperature.

Fig. 6. XRD of $\mathrm{H}_{2} \mathrm{O}$ washed and $\mathrm{H}$-form titanate nanowires (upper part) and $\mathrm{Au}$ loaded $(2.5 \%)$ nanowires (lower part) as a function of annealing temperature.

Fig. 7. TEM images of $\mathrm{H}$-form nanotubes (A) and $\mathrm{H}$-form nanowires (B) at different temperatures.

Fig. 8. HRTEM images of H-form titanate nanotubes (A) and Au containing (2.5\%) nanotubes after different heat treatments; B $-473 \mathrm{~K}, \mathrm{C}-673 \mathrm{~K}, \mathrm{D}-873 \mathrm{~K}$.

Fig. 9. HRTEM images of $\mathrm{H}$-form titanate nanowires (A) and Au containing (2.5\%) nanowires after different heat treatments; B $-473 \mathrm{~K}, \mathrm{C}-673 \mathrm{~K}, \mathrm{D}-873 \mathrm{~K}$.

Fig. 10. HRTEM images of Au containing (2.5\%) nanowires (obtained by $\mathrm{NaBH}_{4}$ reduction). H-form titanate nanowires (A) and after different heat treatments; $\mathrm{B}-473 \mathrm{~K}, \mathrm{C}-$ $673 \mathrm{~K}, \mathrm{D}-873 \mathrm{~K}$. 


\section{Highlights}

$\mathrm{Au}$ is stabilized on titanate nanowires partially in positively charged gold form and also as $\mathrm{Au}$ clusters. Au loaded nanotubes loose their tubular morphology and are readily transformed into anatase. On the other hand, gold stabilizes the layered structure of titanate nanowires.

$\mathrm{ToC}$

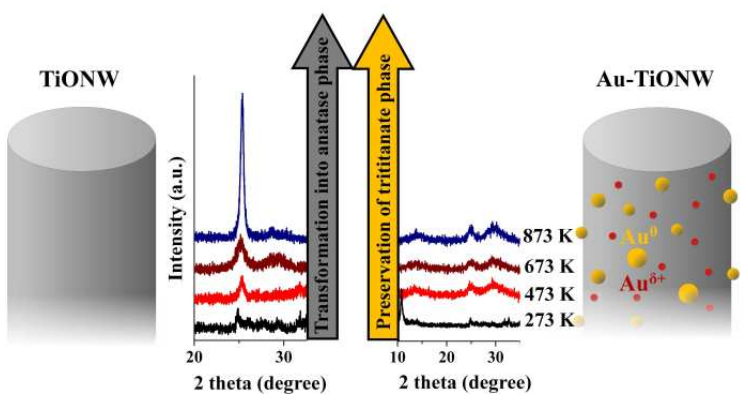




\section{ToC}

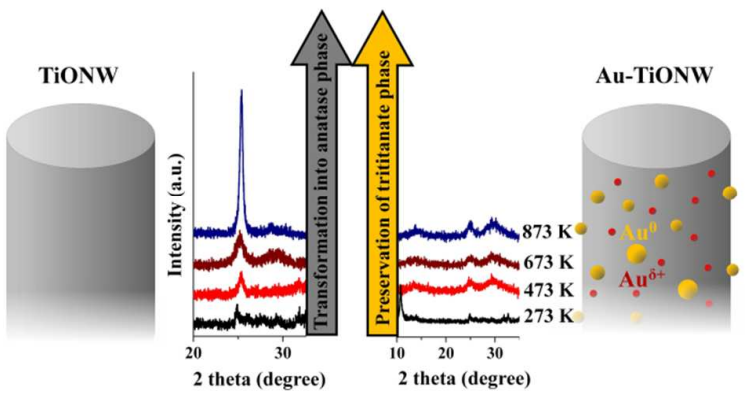


Figure 1
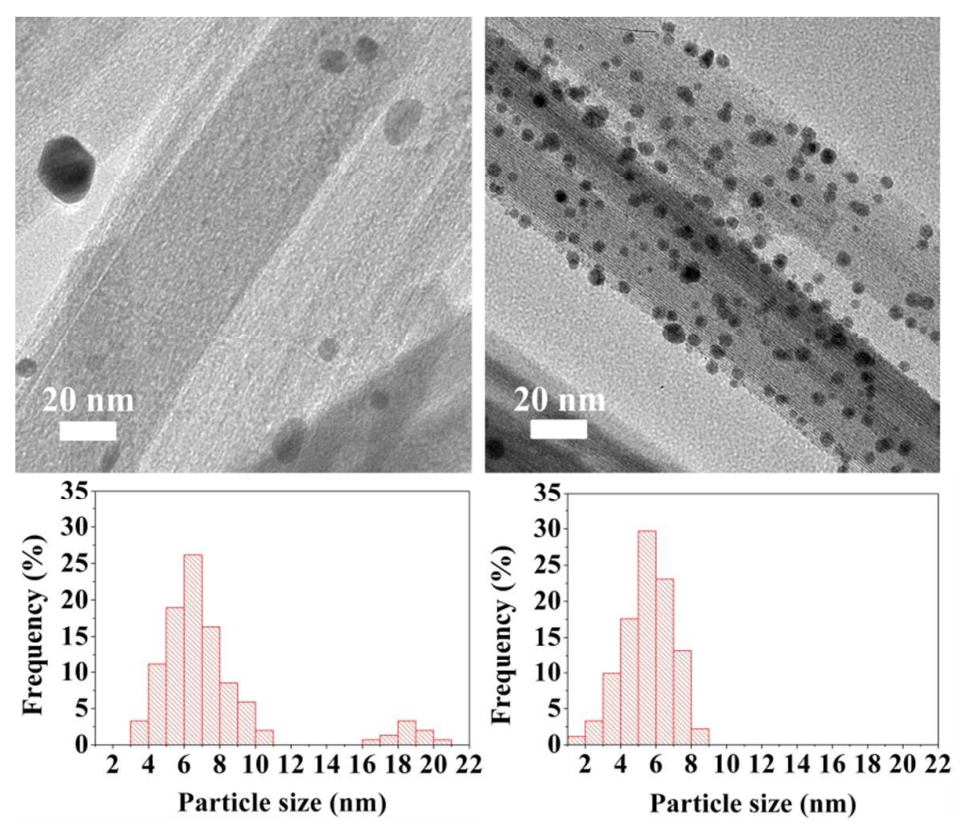

Fig. 1. HRTEM image on Au decorated $\mathrm{H}$-form titanate nanowires obtained with $\mathrm{H}_{2}$ reduction (A) and obtained with $\mathrm{NaBH}_{4}$ reduction (B). The corresponding particle size distributions are also shown. The gold contents were $2.5 \mathrm{wt} \%$ in both cases. 
Figure 2

$\mathrm{Au} 4 \mathrm{f}$
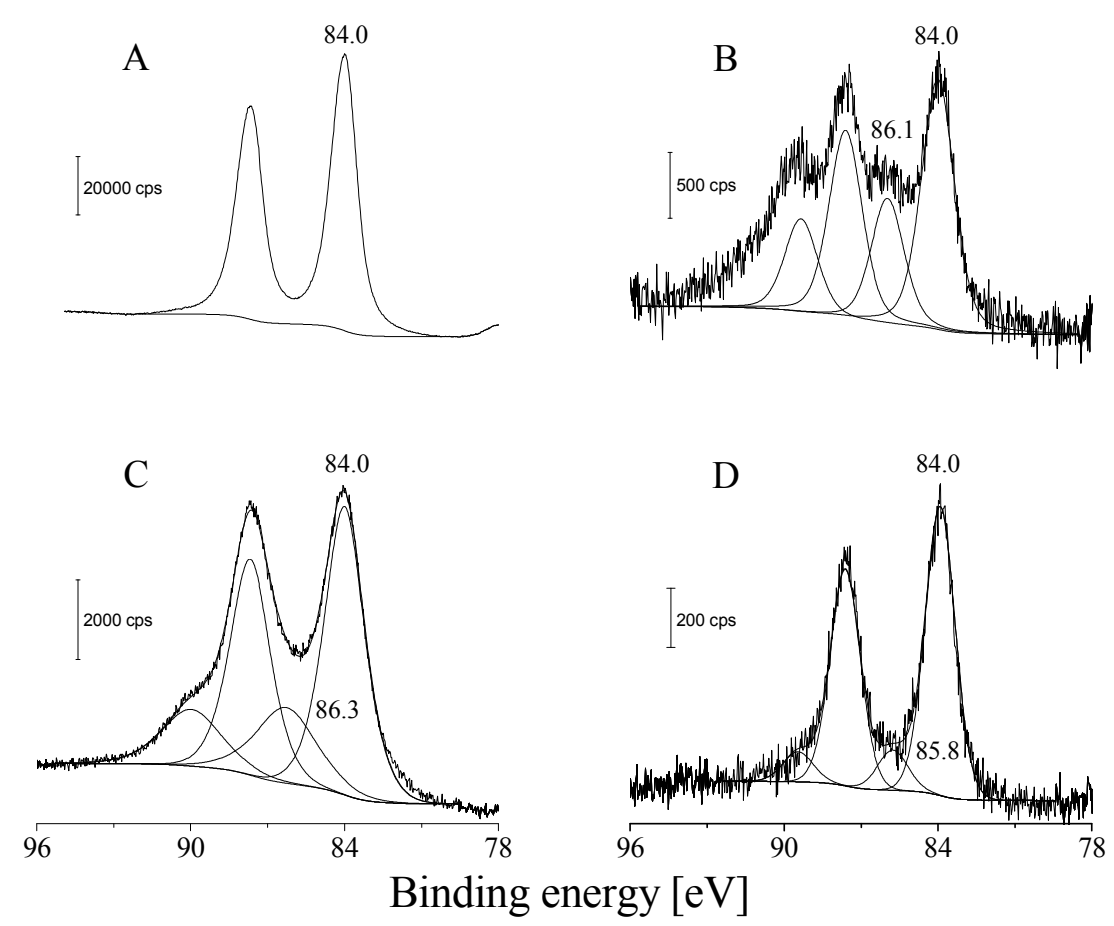

Fig. $2 \mathrm{Au}$ 4f XPS on differentially prepared Au/titanate samples: (A) clean Au film, (B) 1 wt $\% \mathrm{Au} /$ titanate nanowire obtained by $\mathrm{H}_{2}$ reduction at $473 \mathrm{~K}$, (C) $2.5 \mathrm{wt} \%$ Au/titanate nanowire obtained by $\mathrm{H}_{2}$ reduction at $473 \mathrm{~K}$, (D) $2.5 \% \mathrm{Au} /$ titanate nanowire obtained by $\mathrm{NaBH}_{4}$ reduction at $293 \mathrm{~K}$. 
Figure 3

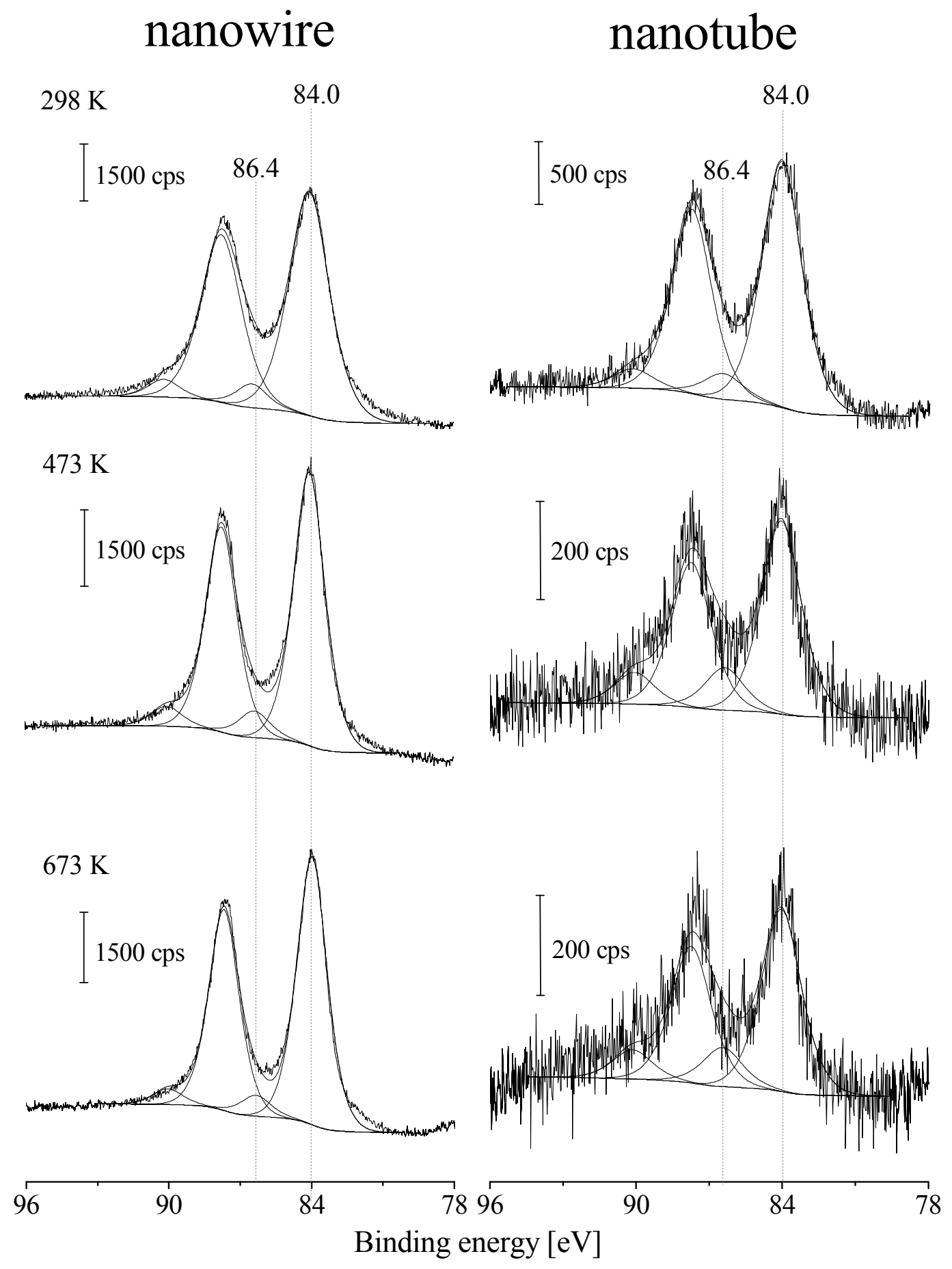

Fig. 3. Au 4f XPS on Au loaded H-form titanate nanowires (A) and nanotubes (B) at $2.5 \mathrm{wt} \%$ gold content after heat treatment in vacuum for $60 \mathrm{~min}$. 
Figure 4
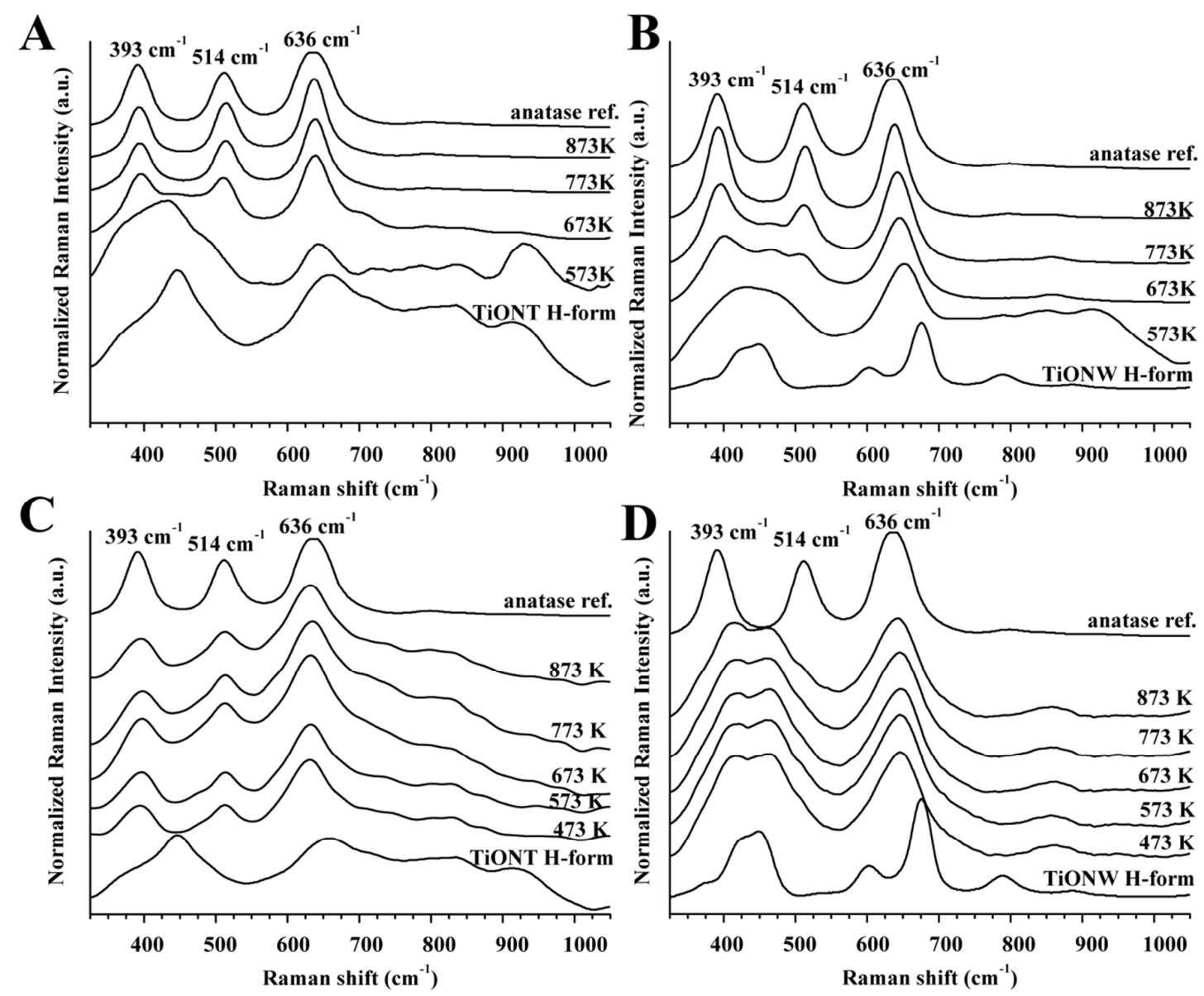

Fig. 4. Normalized Raman spectra of the thermal behavior of $\mathrm{H}$-form titanate nanotubes (A) and nanowires (B). Graphs C and D illustrate the thermal behavior of Au loaded titanate nanotubes and wires, respectively. The commercial anatase reference sample is shown at the top of each spectra. 
Figure 5

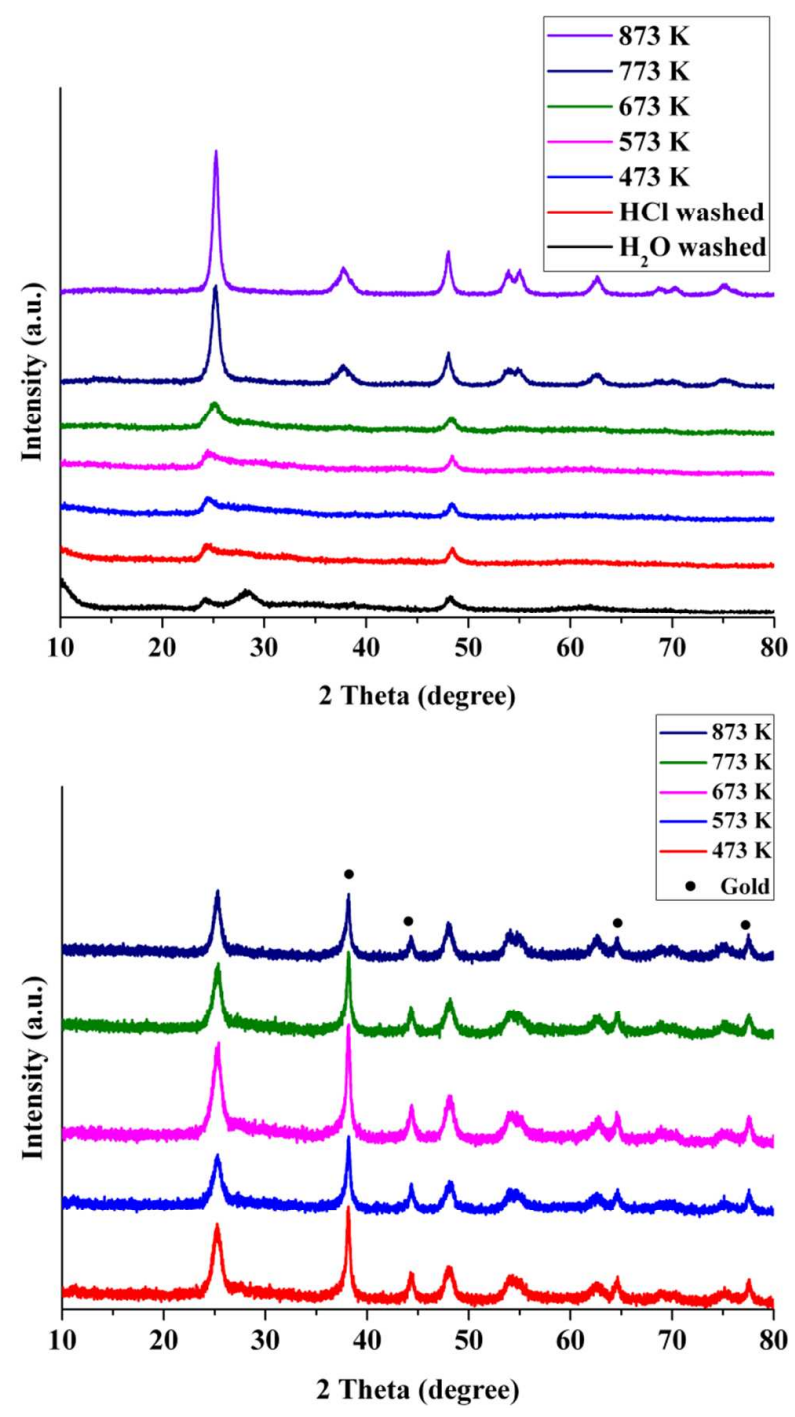

Fig. 5. XRD of $\mathrm{H}_{2} \mathrm{O}$ washed and $\mathrm{H}$-form titanate nanotubes (upper part) and $\mathrm{Au}$ loaded $(2.5 \%)$ nanotubes (lower part) as a function of annealing temperature. 
Figure 6
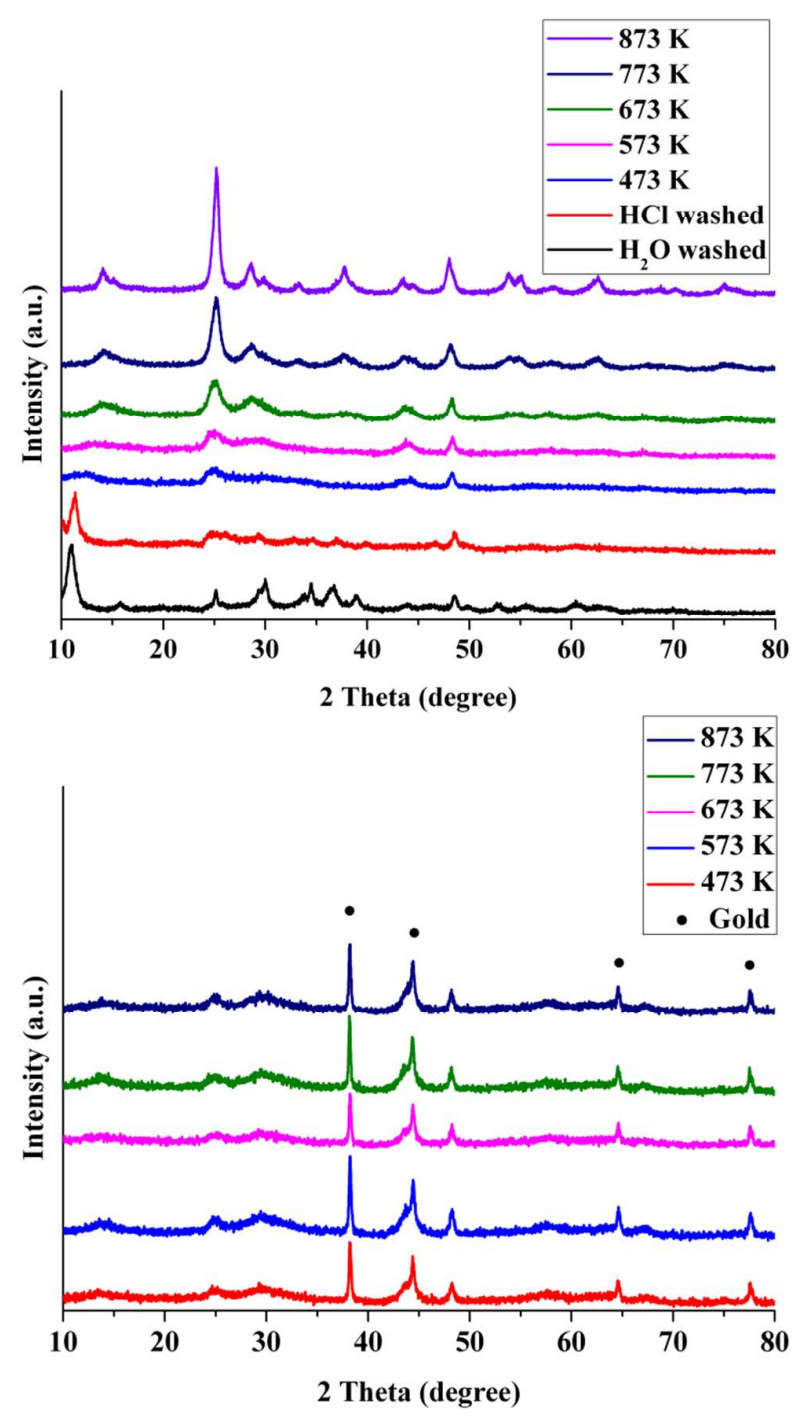

Fig. 6. XRD of $\mathrm{H}_{2} \mathrm{O}$ washed and $\mathrm{H}$-form titanate nanowires (upper part) and $\mathrm{Au}$ loaded $(2.5 \%)$ nanowires (lower part) as a function of annealing temperature. 
Figure 7

A

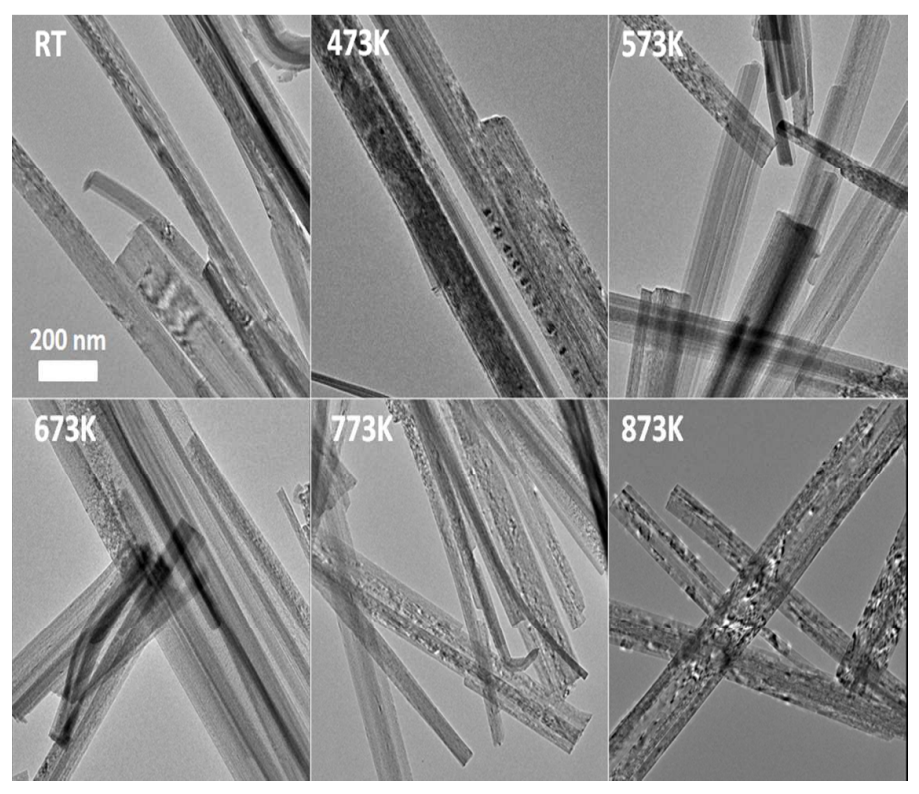

B

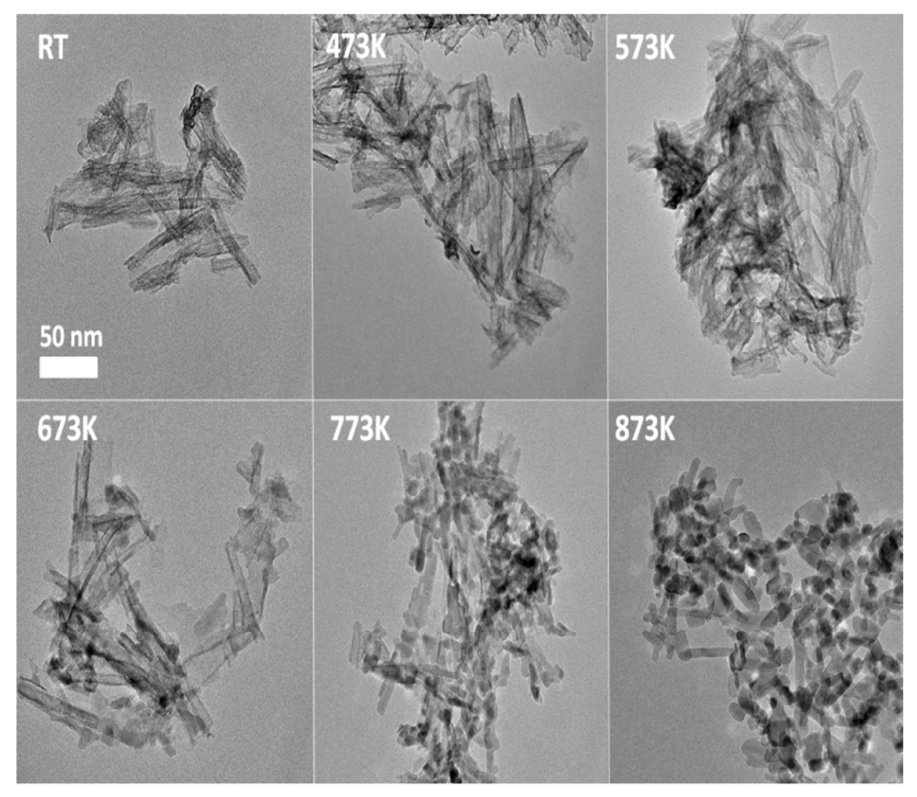

Fig. 7 TEM images of $\mathrm{H}$-form nanotubes (A) and $\mathrm{H}$-form nanowires (B) at different temperatures. 
Figure 8
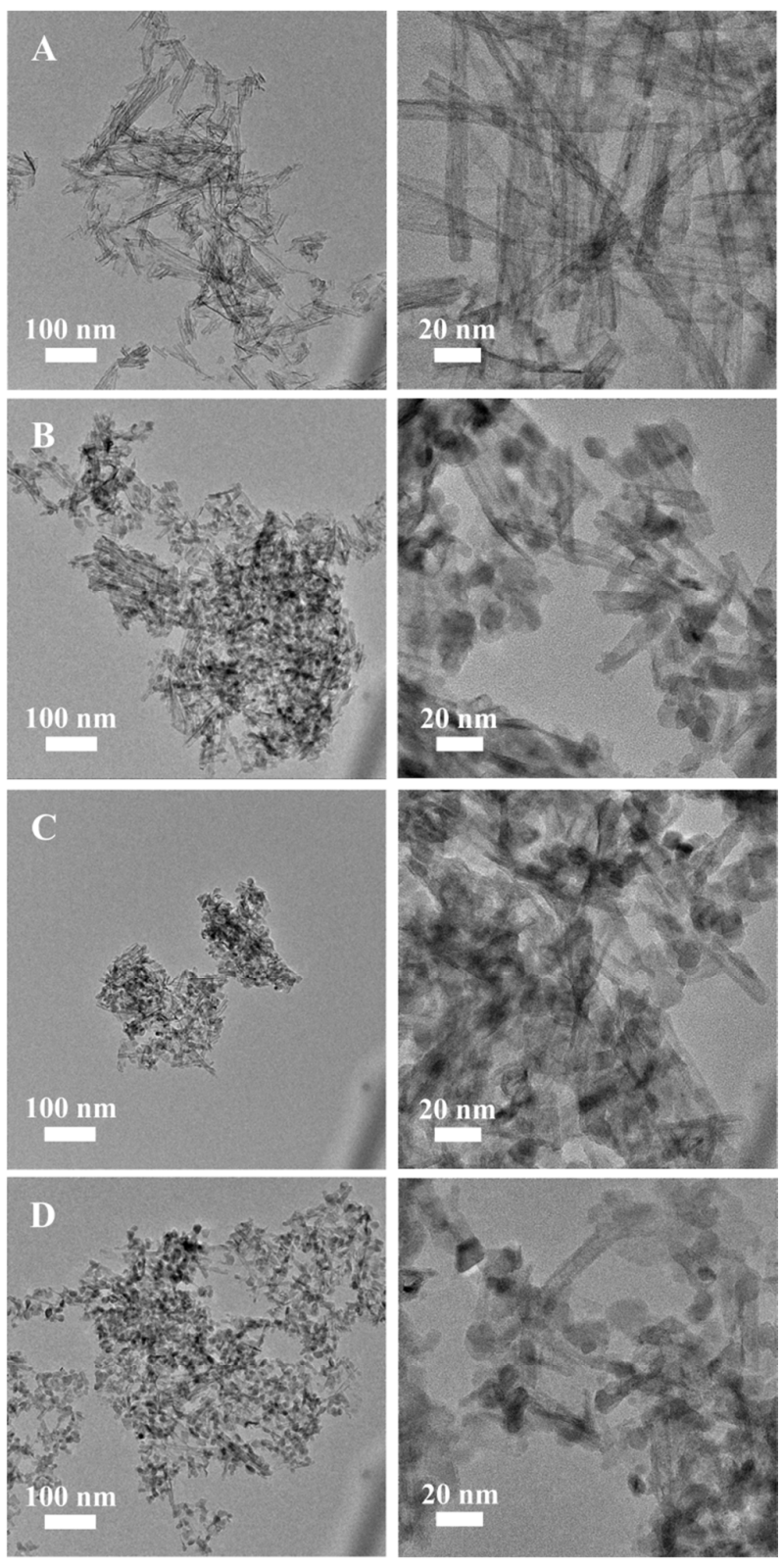

Fig. 8. HRTEM images of H-form titanate nanotubes (A) and Au containing (2.5\%) nanotubes after different heat treatments; B $-473 \mathrm{~K}, \mathrm{C}-673 \mathrm{~K}, \mathrm{D}-873 \mathrm{~K}$. 
Figure 9
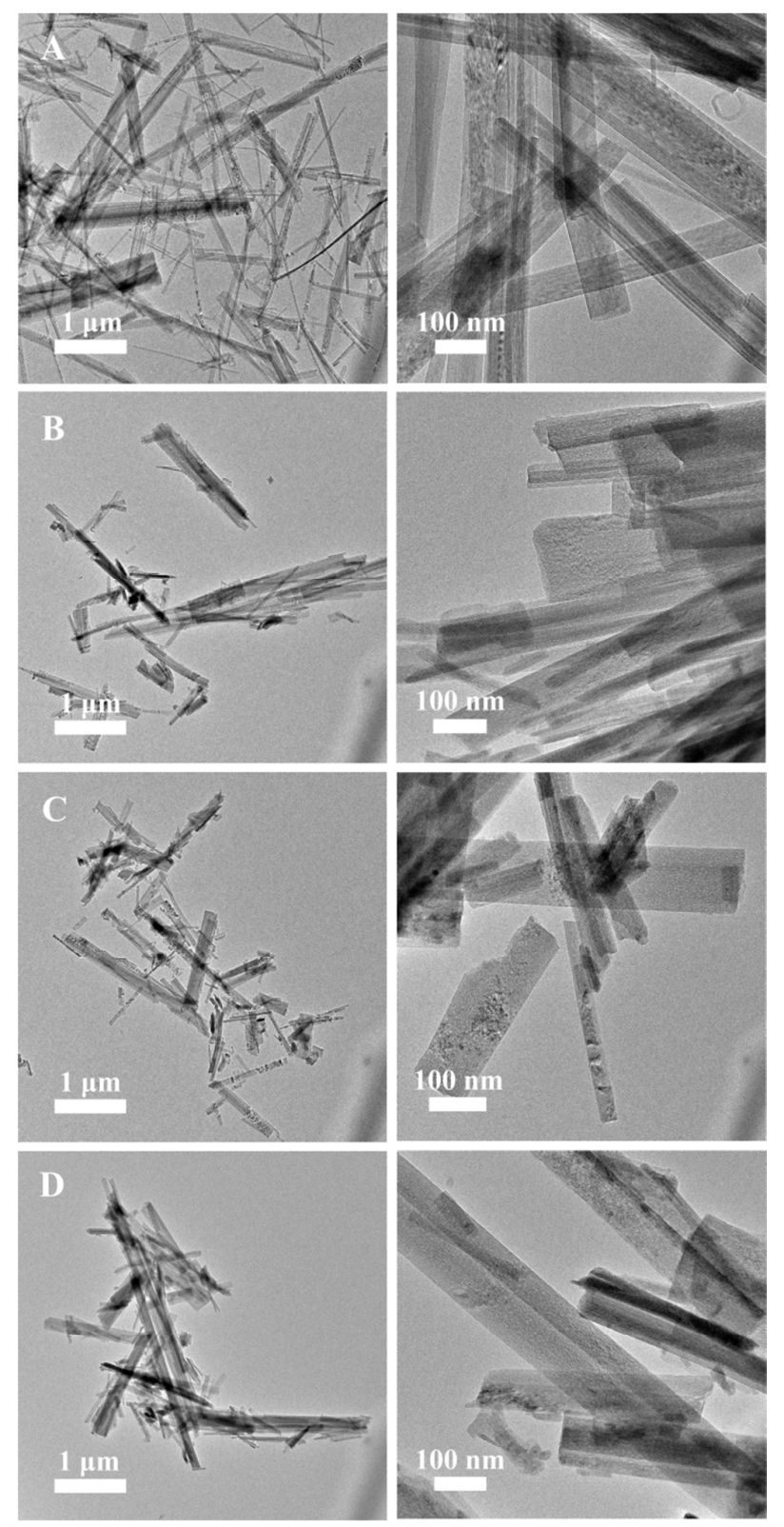

Fig. 9. HRTEM images of H-form titanate nanowires (A) and Au containing (2.5\%) nanowires after different heat treatments; B $-473 \mathrm{~K}, \mathrm{C}-673 \mathrm{~K}, \mathrm{D}-873 \mathrm{~K}$. 
Figure 10
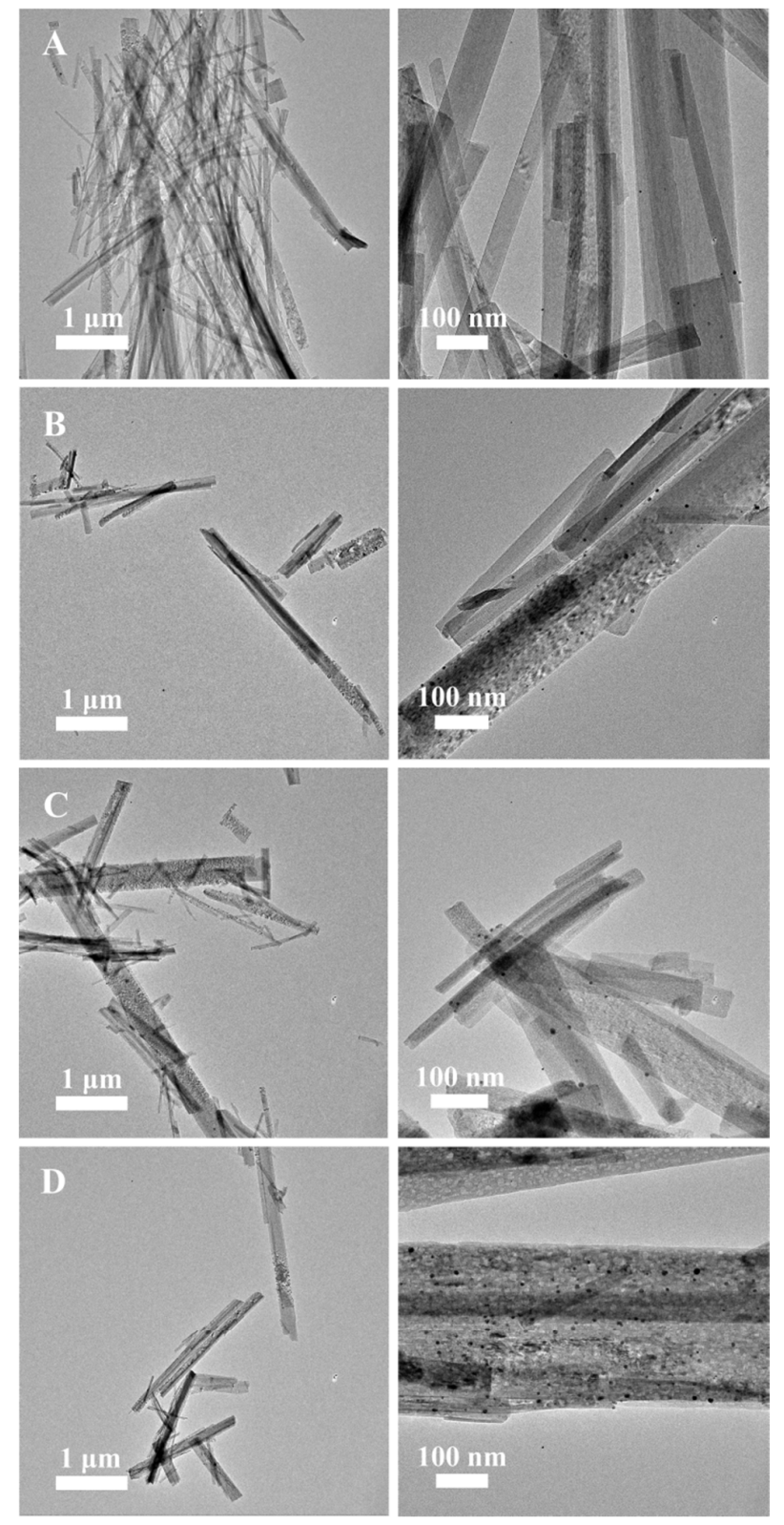

Fig. 10. HRTEM images of Au containing (2.5\%) nanowires (obtained by $\mathrm{NaBH}_{4}$ reduction). H-form titanate nanowires (A) and after different heat treatments; $\mathrm{B}-473 \mathrm{~K}, \mathrm{C}-$ 673 K, D - 873 K. 


\title{
DEPARTMENT OF PHYSICAL CHEMISTRY AND MATERALS SCIENCE MTA-SZTE REACTION KINETICS AND SURFACE CHEMISTRY RESEARCH GROUP OF THE HUNGARIAN ACADEMY OF SCIENCES
}

\author{
Prof. Dr. János Kiss \\ UNIVERSITY OF SZEGED \\ 6701 Szeged, Aradi v square 1. \\ Hungary
}

Address: P. O. Box 168. Tel.: 36-62-544-803 Fax: 36-62-544-106

http:www.staff.u-szeged.hu/ jkiss/

E-mail: jkiss@chem.u-szeged.hu

Sept. 05, 2014

\section{Dr. Anna Simpson}

\section{Editor}

\section{Physical Chemistry Chemical Physics}

Dear Dr Simpson,

Enclosed please find our manuscript entitled „, Influence of Gold Additive on the Stability and Phase Transformation of Titanate Nanostructures" which is submitting for publication in Physical Chemistry Chemical Physics. We hope that our manuscript matches well in your profile.

This present paper is a continuation of our previous works, where we studied the formation, characterization of nanosized metal particles on titanate nanowires and nanotubes and their effects on stability and phase transformation of titanate nanostructures. See examples:

"Metal loading determines the stabilization pathway for $\mathrm{Co}^{2+}$ in titanate nanowires: ion exchange vs. cluster formation" paper was published in PCCP $(2013, \mathbf{1 5}, 15917-15925)$ and "Rh-induced Support Transformation Phenomena in Titanate Nanowire and Nanotube Catalysts" was published in Langmuir (2013, 29, 3061-3072).

I am the corresponding author. The submission and revision process will be handled by me (email: jkiss@chem.u-szeged.hu). In case of any questions please don’t hesitate to contact me.

Best regards

Prof. János Kiss 